\title{
Macroscopic fossils of microbial communities in Eoarchean-Hadean jasper from the Nuvvuagittuq Supracrustal Belt
}

\author{
DOMinic PaPineau ${ }^{12}$,ZHeNBing ShE ${ }^{2}$, MatTHew S. \\ DODD $^{2}$, FRANCESCO IACOVIELLO ${ }^{3}$, ZHONGWU LAN $^{4}$, \\ ERIK HAURI ${ }^{5}$, PAUl SHEARING ${ }^{3}$, CRISPIN T.S. LITTLE ${ }^{6}$ \\ ${ }^{1}$ London Centre for Nanotechnology, Department of Earth \\ Sciences, and Centre for Planetary Sciences, University \\ College London, UK, d.papineau@ucl.ac.uk \\ ${ }^{2}$ State Key Laboratory of Biogeology and Environmental \\ Geology, School of Earth Sciences, China University of \\ Geosciences, Wuhan, China \\ ${ }^{3}$ Department of Chemical Engineering, University College \\ London, UK \\ ${ }^{4}$ Institute of Geology and Geophysics, Chinese Academy of \\ Sciences, Beijing, China \\ ${ }^{5}$ Department of Terrestrial Magnetism, Carnegie Institution \\ for Science, Washington DC, United States, (Deceased) \\ ${ }^{6}$ School of Earth and Environment, University of Leeds, \\ Leeds, UK
}

The oldest known microbial fossils occur as microscopic haematite filaments and tubes in a jasper-carbonate nodule from the banded iron formation (BIF) in the $>3.75 \mathrm{Ga}$, and possibly up to $4.28 \mathrm{Ga}$, Nuvvuagittuq Supracrustal Belt in Canada. However, the microfossil complexity, community organisation, and possible metabolisms remain to be documented. Newly observed haematitic microfossil specimens from a nodule in this BIF occur as centimetresized pectinate-branching and parallel-aligned filaments. Optical images further reveal that some of these have a twisted morphology and are enclosed inside haematite tubes. Decorating the arborescent structure, there are also granules of coarse quartz that contain dozens of oblate spheroids composed of haematite. X-ray-based imaging reveals filaments inside the dense and opaque Fe-oxides, as well as millimetre-long twisted filaments. Associated accessory minerals have geochemical compositions consistent with a biological origin. For instance, filaments often contain ferrous iron in haematite, consistent with diagenetic experiments of the thermal alteration of Fe-oxidising bacterial filaments. Associated calcite rosettes have ${ }^{13} \mathrm{C}$-depletions around $-11 \%$, which points to the oxidation of biomass during diagenesis. Outsized chalcopyrite crystals contain inclusions of apatitegalena, which demonstrate the ancestry of the apatite and $\mathrm{Pb}$ loss during metamorphism. Sulphides in the jasper-carbonate BIF also have ${ }^{33} \mathrm{~S}$ - and ${ }^{34} \mathrm{~S}$-enrichments consistent with an anoxic atmosphere and with microbial sulfur disproportionation. Collectively, the new observations suggest the Nuvvuagittuq microbial communities included photoferrotrophic and S-disproportionating microorganisms. This well-preserved microbial ecosystem is the oldest known on Earth, could be common on other planets with hydrothermal activity, and increases the probability for the widespread existence of extra-terrestrial life. 